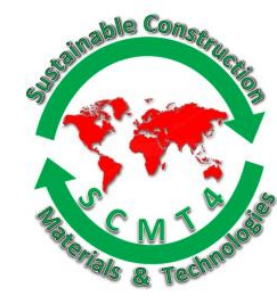

SCMT4

Las Vegas, USA, August7-11, 2016

\title{
Effect of Using Recycled Concrete as Coarse Aggregate on Tensile and Flexural Strength of Concrete
}

\author{
Liaqat A. Qureshi' ${ }^{1 \mathrm{a}}$, M. Jahangeer Munir ${ }^{1 \mathrm{~b}}$, Tahir Mubeen ${ }^{1 \mathrm{c}}$ and Raja M. Tasaddiq ${ }^{1 \mathrm{~d}}$ \\ ${ }^{1}$ Department of Civil Engineering, University of Engineering \& Technology, Taxila, Pakistan \\ ${ }^{1 a}$ Email: <liaqat.qureshi@uettaxila.edu.pk>, ${ }^{1 b}$ Email: <jahan_2003@hotmail.com>, \\ ${ }^{1 c}$ Email: 〈tahirmubeen@hotmail.com>, ${ }^{1 d E m a i l: ~\langle r a j a t a s a d d i q 2010 @ y a h o o . c o m>. ~}$
}

\begin{abstract}
Recycled coarse aggregates include crushed, graded inorganic particles treated from the materials used in old constructions and demolition rubbish. When natural coarse aggregates are replaced by recycled coarse aggregates, strength properties of concrete are decreased to some extent. The basic aim of this research was to investigate the effect of using recycled concrete pieces as coarse aggregate on flexural and tensile strength of concrete. The investigation was carried out by carrying out split cylinder and flexural strength tests on six batches of concrete mixes prepared by using $20 \%$ increment of natural coarse aggregate replacement from $0 \%$ to $100 \%$ by recycled coarse aggregates. The results showed a gradual decrease in tensile and flexural strength properties as the percentage of recycled coarse aggregate used in the specimens increased. After the induction of a super plasticizer (RHEOBUILD 850), loss in flexural strength was more than compensated successfully.
\end{abstract}

\section{INTRODUCTION}

Construction materials play a vital role in our lives, because we spend $90 \%$ of our time in buildings or Infrastructures like highways, roads, bridges, etc. Recycling is the act of reprocessing the utilized materials in producing new products. The utilization of natural aggregates is getting more and more intension in construction industry with the advanced development in infrastructure field. Recycled coarse aggregates can be utilized as substitute materials in order to decrease the cost of natural coarse aggregates. Recycled coarse aggregates consist of crushed material developed from the demolition and construction debris. These materials are taken generally from bridges, roads, buildings, and even from catastrophes such as earthquakes and wars. Recycling of old "Portland Cement Concrete Pavements (PCCP)" as aggregates in new PCCP construction is proved as a substitute construction method in current years on many grounds. This method often decreases total transportation cost for materials on a paving project; it also reduces drain on sometimes restricted local natural aggregate supply; and it removes the increasingly serious environmental problem of appropriate disposal of left over concrete. Inclusion of old concrete as aggregate in new concrete is a feasible option resulting in the development of new concrete possessing those characteristics required to perform adequately in the service conditions and neighboring environment. For highway pavements, these circumstances may consist of extreme temperature, freezing and thawing, chemical attack by solutions of natural and deicer materials and moisture effects, all often made worst by surface wearing traffic load 
effects. Current faulting and cracking problems arising in jointed concrete pavements developed with recycled coarse aggregate concrete led to an assessment of some of the basic mechanical and physical properties of such concrete, even though many of these properties had been previously considered. In the laboratory investigation, many properties of recycled and virgin concrete were studied including split tensile strength and flexural strength.

In concrete construction industry, there is widespread utilization of concrete recycled coarse aggregates. Study on recycled coarse aggregates has carried out in several countries since 1945[Hanson and Narud 1983]. Relative density of RCA is found to be 7 to $9 \%$ less and water absorption to be two times higher than NCA [Limbachiyaet al. 2000]. Depending on the results, there was no effect on strength with the $30 \%$ replacement by recycled concrete and RCA could be successfully utilized in normal strength properties concrete. They also mentioned that in high-strength concrete mixes, RCA can be utilized without any hesitation. The difference between the fresh and hardened RCA and NCA in the field is relatively narrower than the laboratories crush RCA mixes [Sagoe et al. 2002]. There is no difference in the 5\% replacement level on concrete compressive and tensile strength properties of RCA and controlled normal concrete from natural resources. Mandal et al.[2002] found that there were no consequences on concrete strength properties with replacement up to $30 \%$ recycled coarse aggregates. But the cubical strength properties were gradually decreased when the quantity of recycled material replacement was increased. Limbachiya et al. [2004] also came to the conclusion that there was no affect on a standard 100-mm concrete cubic compressive strength using 30\% recycled coarse aggregate materials. When the amount of recycled concrete aggregate was increased, the compressive strength properties were reduced.

According to Tavakoliand Soroushian[1996], the effect of recycled coarse aggregate content on the original concrete strength properties depends upon different factors like the ratio between fine aggregate to coarse aggregate in the original concrete, and the ratio between the upper part of the size of the recycled coarse aggregate in the original aggregates. Los Angeles friction losses have influence on the w/c ratio and top of the size ratio to hold the properties of recycled coarse aggregate concrete. According to Bodin and Zaharieva [2002], the decrease in the strength properties of recycled coarse aggregate concrete sample was due to the higher w/c ratio, which was used for workability. By Takehino and Nishi [2010], it was established that post-consumer recycled coarse aggregate concrete strength could be increased with the utilization of local materials that can absorb more water. Mandalet al. [2002] uttered that by regulating w/c ratio in the utilization of recycled coarse aggregate in concrete, durability of recycled coarse aggregate concrete can be increased. The test results by Chen et al. [2003] showed that building debris could be converted into useful recycled aggregates through suitable treatment. Strength of concrete would be affected by using unwashed recycled aggregates. At lower w/c ratios, the effect would be more evident. Negative effects were significantly enhanced when recycled aggregates were washed.

In current research program, the concrete wastes collected by the commercial testing of concrete cubes, cylinders and beams in the lab were manually converted into small pieces of different standard size ranges of coarse aggregate. Different replacement ratios of these recycled concrete coarse aggregates were utilized in casting standard samples to study the strength properties of concrete.

\section{EXPERIMENTAL PROGRAM}

\section{Materials}

The materials utilized in the research program are described here:

\section{Cement}

The cement utilized was type I ordinary Portland cement. The chemical composition of the cement used is given in Table 1. 
Table 1. Chemical Composition of Ordinary Portland Cement

\begin{tabular}{|c|c|c|c|}
\hline Compound & Value (\%) & Compound & Value (\%) \\
\hline $\mathrm{CaO}$ & 64.25 & LOI & 0.64 \\
\hline $\mathrm{Al}_{2} \mathrm{O}_{3}$ & 5.5 & $\mathrm{Na} 2 \mathrm{O}$ & 0.2 \\
\hline $\mathrm{Fe}_{2} \mathrm{O}_{3}$ & 3.5 & $\mathrm{~K} 2 \mathrm{O}$ & 1 \\
\hline $\mathrm{SiO}_{2}$ & 22 & $\mathrm{SO} 3$ & 2.9 \\
\hline $\mathrm{MgO}$ & 2.5 & - & - \\
\hline
\end{tabular}

\section{Fine Aggregate}

The fine aggregate utilized in the research work was locally available Lawrencepur brand Pakistani sand. Sieve analysis of the sample was carried out according to ASTM C136-06 in the concrete laboratory of Civil Engineering Department UET Taxila. The value of fineness modulus was found to be 2.50 calculated as the sum of cumulative percentages retained on different sieves. The specific gravity of the sand was calculated as 2.71 (ASTM C128-79) and the water absorption of sand during 24 hours was calculated as $1.20 \%$ (ASTM C128-01).

\section{Coarse Aggregate}

Best quality Margalla brand coarse aggregate and recycled crush were utilized in the research. The recycled crush was produced by using waste developed by the commercial testing of cubes, cylinders, beams in the concrete lab. Waste material was broken into small pieces manually by hammer and chisel to different standard sizes of coarse aggregates. These sizes were then separated by passing through sieves of different sizes and utilized as coarse aggregates as per British Standard BS 410: 1962. Recycled concrete aggregates were utilized while casting concrete samples as per original concrete mix design with the replacement ratios of $0,20,40,60,80, \& 100$ percent of natural coarse aggregates. Samples were cast to carry out split cylinder strength and flexural strength tests.

Sieve analysis of coarse aggregates was carried out as per ASTM C136-06.The bulk specific gravity test for natural coarse aggregates was carried out conforming to ASTM C 127-81. It gave bulk specific gravity of natural coarse aggregates as 2.68 . The water absorbed by natural coarse aggregates during 24 hours was calculated using procedure given in ASTM C127-12 as 0.80\%. The moisture content of natural coarse aggregates was also calculated using procedure given in ASTM C 566-78. It was noted that the aggregates have $1 \%$ moisture content. So the aggregates were assumed to be dry as the moisture content percentage was below $10 \%$.

\section{Water}

The water utilized for mixing of mortar and concrete was ordinary tap water of concrete laboratory in U.E.T. Taxila. The characteristics of water utilized are given in Table 2.

Table 2. Characteristics of Lab water

\begin{tabular}{|c|c|c|c|c|c|}
\hline \multirow{2}{*}{ S. No. } & Source Description & pH Value & $\begin{array}{c}\text { Hardness }\left(\mathrm{CaCo}_{3}\right) \\
(\mathrm{mg} / \mathrm{l}))\end{array}$ & $\begin{array}{c}\text { Chloride } \\
(\mathrm{mg} / \mathrm{l})\end{array}$ & $\begin{array}{c}\text { Sulfate }\left(\mathrm{SO}_{4}{ }^{-2}\right) \\
(\mathrm{ppm})\end{array}$ \\
\hline 1. & Tap water & 7 & 300 & 240 & 45 \\
\hline $\begin{array}{l}\text { Maximum permissible limit as per } \\
\text { WHO guidelines }\end{array}$ & 6.5 to 8.5 & 500 & 250 & 400 \\
\hline
\end{tabular}




\section{Admixture}

BASF RHEOBUILD 850 was used in the research program as admixture. It is derived from synthetic polymers particularly designed to give rheoplastic qualities to concrete. Typical properties of RHEOBUILD 850 are given as under:

Color: Dark brown

Freezing point: $0^{\circ} \mathrm{C}$
Specific gravity: 1.210 at $25^{\circ} \mathrm{C}$

Chloride content: zero
Physical state: liquid

\section{$\underline{\text { Standards }}$}

EN 934-2 Tables 3.1, 3.2, 11.1 and 11.2

ASTM C-494 Type A, B, D, F and G

\section{Casting Schedule}

The detailed casting schedule with mix designations for current research is given in Table 5:

Table 3. Detail of mixes

\begin{tabular}{|c|c|c|}
\hline S. No. & Designation of Mix & Mix. Details \\
\hline 1 & TR-1 & $100 \%$ NA* \\
\hline 2 & TR-2 & $20 \% \mathrm{RA}^{* *}+80 \%$ NA \\
\hline 3 & TR-3 & $40 \%$ RA $+60 \%$ NA \\
\hline 4 & TR-4 & $60 \%$ RA+ $40 \%$ NA \\
\hline 5 & TR-5 & $80 \%$ RA+ $20 \%$ NA \\
\hline 6 & TR-6 & $100 \%$ RA+ $100 \%$ NA \\
\hline 7 & TR-7 & TR-6with1.2\% admixture dose \\
\hline 8 & TR-8 & TR-6with $1.5 \%$ admixture dose \\
\hline
\end{tabular}

${ }^{*} N A$ stands for natural aggregates

${ }^{* *} R A$ stands for recycled coarse aggregates

\section{Casting of Test Samples}

12 cylinders for split tensile strength test and 3 beams for flexural strength test were cast TR-1 to TR-6 mixes. Thus, a total of 72 cylinders for split tensile strength properties and 18 beams for flexural strength were cast. After casting, test specimens were de-molded after 24 hours and kept in the curing tanks until the specified time of testing. In second phase, six more beams were cast using super plasticizer, RHEOBUILD 850.Its two doses were tried in the mix of 100 percent recycled concrete aggregate to compensate for the loss in flexural strength. Again flexural strength test was carried out and best dose of admixture giving best results was recommended. Complete casting schedule and details of test specimens are presented in Table 4.

Table 4. Casting schedule and details of Test specimens

\begin{tabular}{|c|c|c|c|c|c|c|c|}
\hline \multirow{2}{*}{ Test Details } & \multirow{2}{*}{ Specimen Details } & \multicolumn{4}{|c|}{ Age (days) } & Total for 1 & Total for all \\
mix & mixes \\
\cline { 3 - 8 } & & 3 & 7 & 28 & 56 & \\
\hline $\begin{array}{c}\text { Split Tensile } \\
\text { Test }\end{array}$ & $\begin{array}{c}\text { Cylinders } \\
(6 \text { in } \times 12 \text { in })\end{array}$ & 3 & 3 & 3 & 3 & 12 & $12 \times 6=72$ \\
\hline $\begin{array}{c}\text { Flexural } \\
\text { Strength Test }\end{array}$ & $\begin{array}{c}\text { Beams } \\
(4 \text { in } \times 4 \text { in } \times 19.5 \text { in })\end{array}$ & -- & -- & 3 & -- & 3 & $\begin{array}{c}3 \times 6=183 \\
\times 2=06\end{array}$ \\
\hline
\end{tabular}




\section{RESULTS \& DISCUSSION}

\section{Tensile Strength}

Split cylinder test was carried out to ascertain tensile strength of standard cylinders cast from each mix. Tensile strength test results show decreasing trend of strength as the percentage of recycled coarse aggregates is increased and percentage of natural coarse aggregates is decreased. Furthermore, it shows that the strength of recycled coarse aggregate specimens is lower than natural aggregate specimens. The results of split cylinder test carried out on samples having mix ratio 1:2:4 and water-cement ratio 0.6 , with different percentages of recycled coarse aggregates are plotted in Figure 1 for all ages of testing i.e., 3, 7, 28, and 56 days.

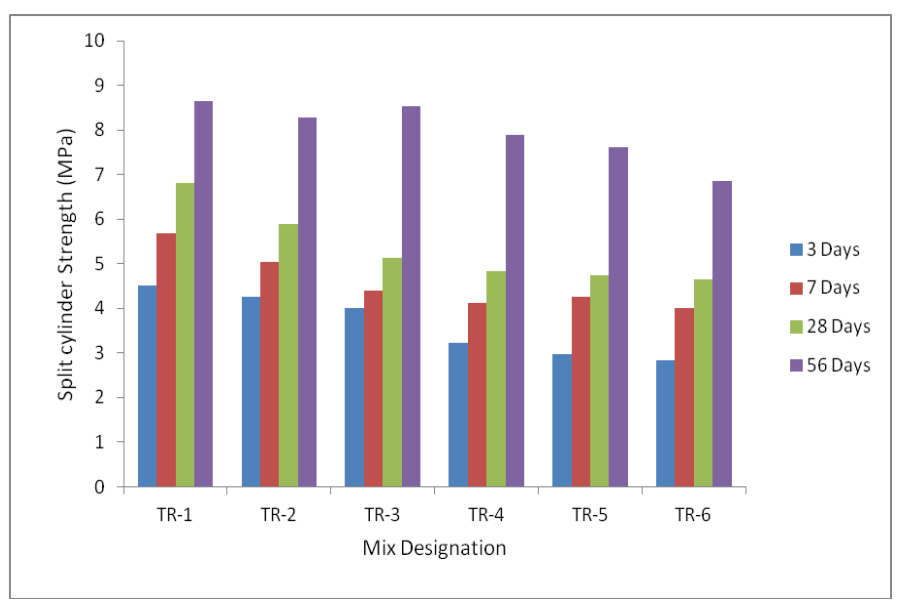

\section{Figure 1. Split cylinder strength of cylinders at all testing ages}

Figure 1 shows that TR-2 drops about $8 \%$ of tensile strength of TR1. TR- 4 drops about $16 \%$ while TR- 6 (with $100 \%$ recycled coarse aggregates) drops $25 \%$ of tensile strength as compared to the control sample at 3,7,28, and 56 days respectively. Figure 2 shows the comparison of rate of gain of tensile strength as the percentage of recycled coarse aggregates is increased by $20 \%$ in each mix. Each increment drops the strength properties at about $8 \%$ of original mix while with $100 \%$ recycled coarse aggregates approximately $25 \%$ of original tensile strength properties is dropped at all ages. The results also show that the concrete specimens with higher replacement ratio of recycled coarse aggregates have lower value of tensile strength when compared to the concrete specimens with less recycled coarse aggregate.

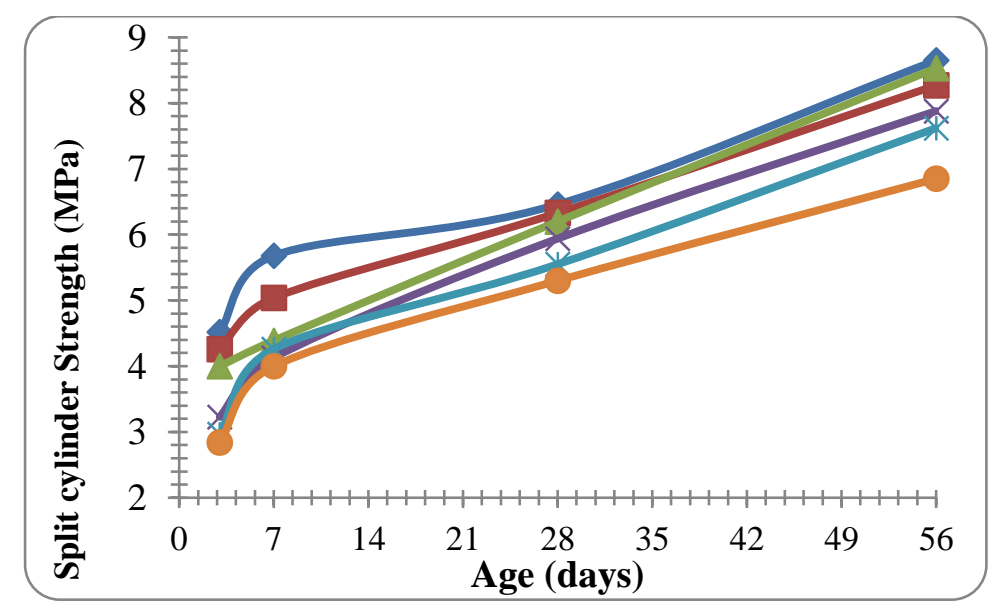

Figure 2. Comparison of rate of gain of split cylinder strength for all mixes 
Figure 2 also reveals that from 3 to 7 days age, the rate of increase in strength is higher for all mixes except TR-3, which shows a medium rate of increase in strength. From 7 to 28 days age, TR-3 shows a steep curve as compared to other mixes while from 28 to 56 days strength, all mixes exhibit same rate of change in strength which is faster than the previous segment.

\section{Flexural Strength}

Flexural strength of standard beams cast from all concrete mixes was measured by modulus of rupture test. This test was carried out by three point loading test. Results show that flexural strength of the concrete for all mixes except that of TR-3 is less than normal but there is no significant trend observed regarding flexural strength of concrete mixes (Figures $3 \& 4$ ). However by introducing the superplasticiser, flexural strength loss was more than compensated in $100 \%$ recycled coarse aggregate concrete (Figures $5 \& 6$ ).

Figure 3 exhibits that flexural strength for TR-2 drops considerably as compared to TR-1 while it is maximum for TR-3. Flexural strength of TR-4 was intermediate while that of TR-5 and TR- 6 was almost equal to that of TR-1. The same is shown in Figure 4 in comparison format.

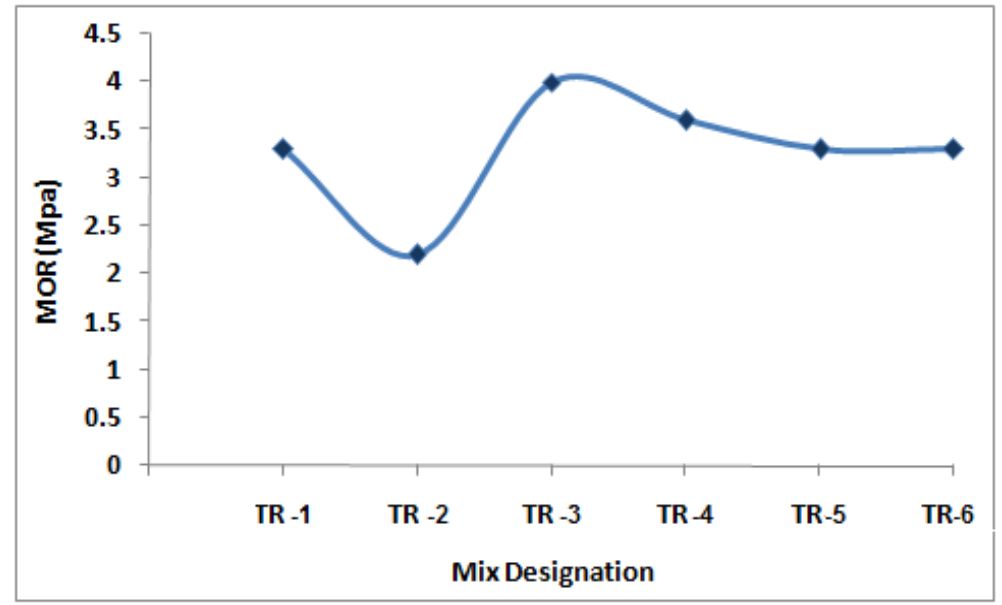

Figure 3. Mix designation versus modulus of rupture of concrete

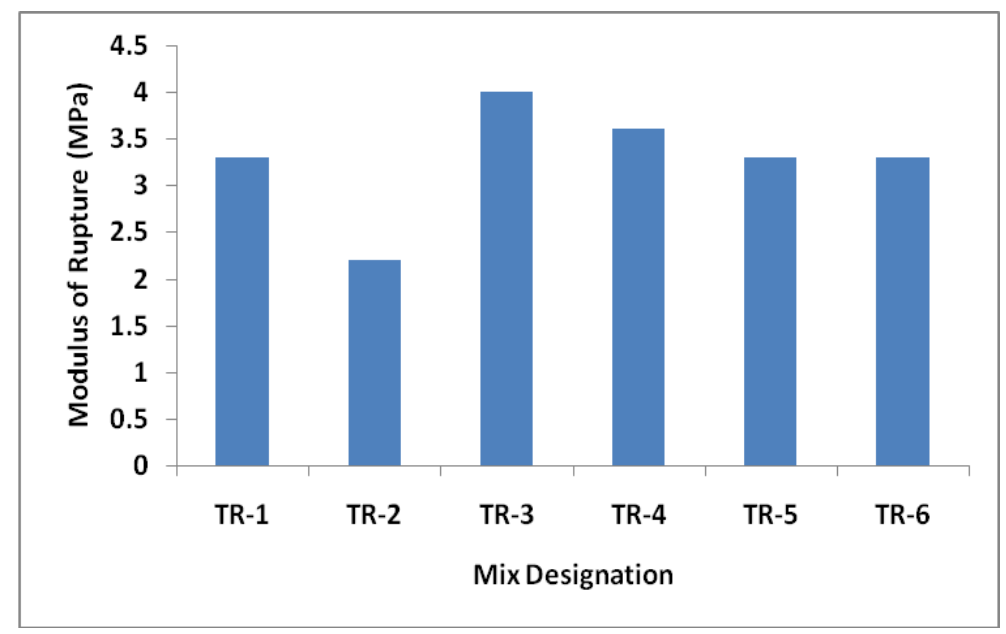

Figure 4. Mix designation versus modulus of rupture of concrete (comparison) 


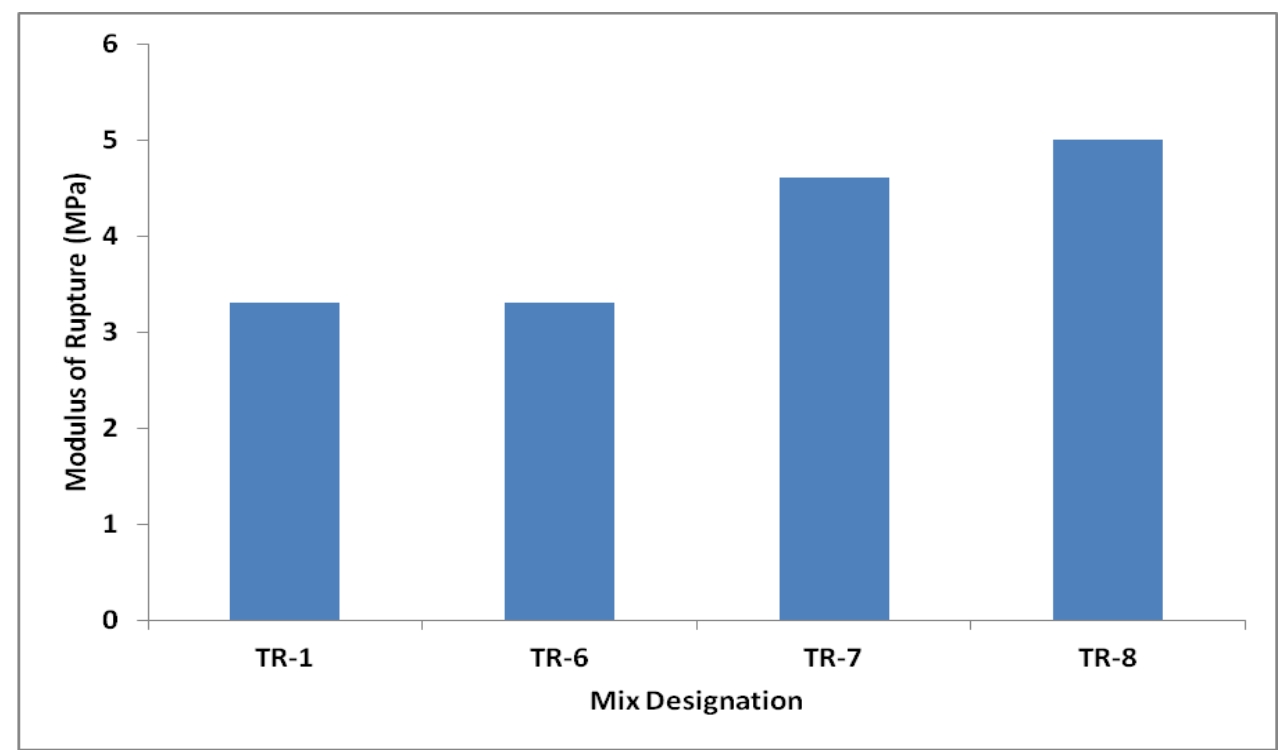

Figure 5. Mix designation versus of modulus of rupture of concrete (comparison)

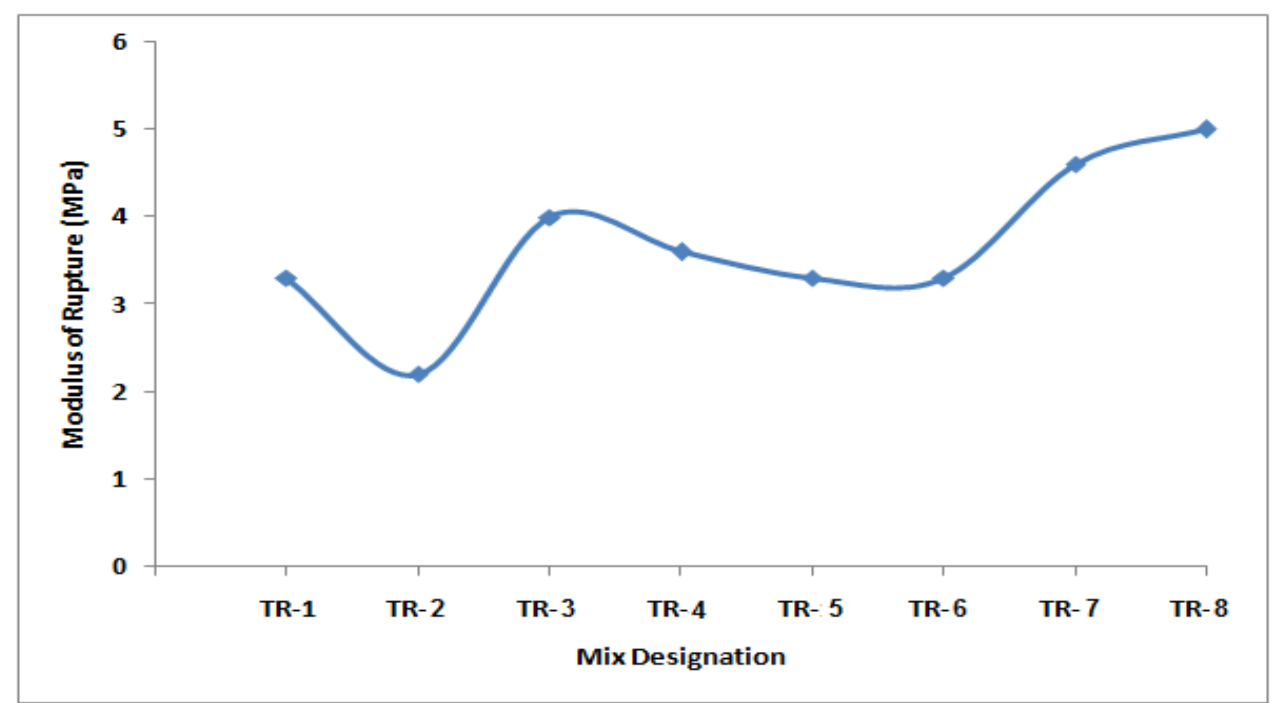

Figure 6. Mix designation versus of modulus of rupture of concrete

Figure 5 and 6 represent the results after addition of admixture in TR- 6 and indicate that flexural strength is sustainably increased. Mixture dose was $1.2 \%$ in TR-7 and $1.5 \%$ in TR-8. Results show that flexural strength of both mixes was even more than TR-1 with $100 \%$ natural aggregates. However, mix with $1.5 \%$ admixture dose showed maximum strength.

\section{COST COMPARISON}

Cost comparison for natural aggregates and $100 \%$ recycled coarse aggregates is given in Table 5 while that for NCA concrete and RCA concrete is in Table 6. 
Table 5. Cost Comparison (Aggregates)

\begin{tabular}{|l|c|c|}
\hline & $\begin{array}{c}\text { Recycled Concrete } \\
\text { Aggregate (Cost per } \\
\text { cft of aggregates in } \\
\text { PKR) }\end{array}$ & $\begin{array}{c}\text { Natural rock Aggregate } \\
\text { (Cost per cft of } \\
\text { aggregates in PKR) }\end{array}$ \\
\hline $\begin{array}{l}\text { Price of raw material, (RM) e.g., Blasting } \\
\text { and allied operations }\end{array}$ & 0 & 4 \\
\hline Cost of crushing the rock material & 6 & 6 \\
\hline Cost of stockpiling the aggregates & 2 & 3 \\
\hline Cost of loading the aggregates & 3 & 10 \\
\hline Cost of transporting the aggregates & 8 & 10 \\
\hline Profit (P) & 8 & 35 \\
\hline Delivered Price (DP) at 50 Km & 27 & \\
\hline
\end{tabular}

Table 6. Cost comparison of $1 \mathrm{~m}^{3}$ of NCA \& RCA concrete (1:2:4)

\begin{tabular}{|l|c|c|c|}
\hline \multirow{2}{*}{} & \multirow{2}{*}{ Quantity } & \multicolumn{2}{|c|}{ Cost } \\
\cline { 3 - 4 } & & $\begin{array}{c}\text { Natural } \\
\text { aggregate concrete }\end{array}$ & $\begin{array}{c}\text { Recycled aggregate } \\
\text { concrete }\end{array}$ \\
\hline Cost of cement & $5.64 \mathrm{bags}$ & 2820 & 2820 \\
\hline Cost of sand & $14 \mathrm{cft}$ & 350 & 350 \\
\hline Cost coarse aggregates & $28 \mathrm{cft}$ & 980 & 756 \\
\hline Total & & 4150 & 3920 \\
\hline
\end{tabular}

It is clear from Tables $5 \& 6$ that if we utilize $100 \%$ recycled coarse aggregates in concrete the overall economy of $23 \%$ can be achieved with only $30 \%$ loss in strength properties.

\section{CONCLUSIONS \& RECOMMENDATIONS}

\section{Conclusions}

1) There is slight decrease in tensile strength of concrete assessed with the help of split cylinder test. The decrease in tensile strength progressively increased by the increase in recycled coarse aggregate percentage. However, it has been observed that there may be $30 \%$ reduction in tensile strength, even if we utilization $100 \%$ recycled coarse aggregates in concrete.

2) All mixes showed same rate of gain of tensile strength for all replacement ratios of recycled concrete coarse aggregates.

3) Proper trend could not be observed in case of flexural strength (Modulus of rupture test).

4) If proper super plasticizer is utilized, decrease in flexural strength in case of $100 \%$ replacement by recycled coarse aggregates, can be more than compensated.

\section{Recommendations}

Recycled concrete aggregates can be confidently utilized in casting new concrete members. However, $1.5 \%$ dose of the admixture 'Rheobuild 850 ' is recommended to get normal strength properties of concrete, even with $100 \%$ replacement of coarse aggregates by recycled coarse aggregates. 


\section{REFERENCES}

ACI Committee 555. (2001). "Removal and Reutilization of Hardened Concrete." ACI Committee Report, American Concrete Institute, Farmington Hills, MI. 18 - 26.

Buyle-Bodin, F., and Hadjieva-Zaharieva, R. (2002). "Influence of industrially produced recycled aggregates on flow properties of concrete." Materials and Structures, 35(8), 504-509.

Chen, H. J., Yen, T., and Chen, K. H. (2003). "Use of building rubbles as recycled aggregates." Cement and Concrete Research, 33(1), 125-132.

Limbachiya, M. C., Leelawat, T., and Dhir, R. K. (2000) "Utilization of recycled concrete aggregate in high-strength properties concrete." Journal of Materials and Structures, 33, 574-580.

Limbachiya, M. C. A., Koulouris, J., Roberts, J., and Fried, A. N. (2004). "Performance of recycled coarse aggregate concrete." Proceedings of RILEM International Symposium on Environment-Conscious Materials Tavakoli, M. and Soroushian, P. (1996). "Strengths of Recycled Aggregate Concrete Made Using Field-Demolished Concrete as Aggregate.” Materials Journal, 93(2), 178-181.

and Systems for sustainable Development." Kingston University UK, Print-ISBN: 2-912143-55-1, RILEM Publications SARL, 127-136.

Mandal, Saroj, Gupta, Arundeb. (2002). "Strength and Durability of Recycled Aggregate Concrete." IABSE Symposium Report, IABSE Symposium, Melbourne 2002: Towards a Better Built Environment - Innovation, Sustainability, Information Technology, Publisher: International Association for Bridge and Structural Engineering, 33-46(14).

Sagoe-Crentsil, K. K., Brown, T., Mak, S.L., and Taylor, A. (1996). "Engineering Properties and Performance of Concrete made with Recycled Construction Aggregates." Proceedings of the National Symposium on the Utilization of Recycled Materials in Engineering Construction, Sydney." May 1996, $132-135$.

Sawamoto, T., and Nishi, K. (2010). "A Study on Recycling of Concrete Waste in Site and Appropriate Mix Proportions." The Bulletin of Institute of Technologists, 1, 39-44.

Tavakoli, M. and Soroushian, P. (1996). "Strengths of Recycled Aggregate Concrete Made Using FieldDemolished Concrete as Aggregate.” Materials Journal, 93(2), 178-181. 